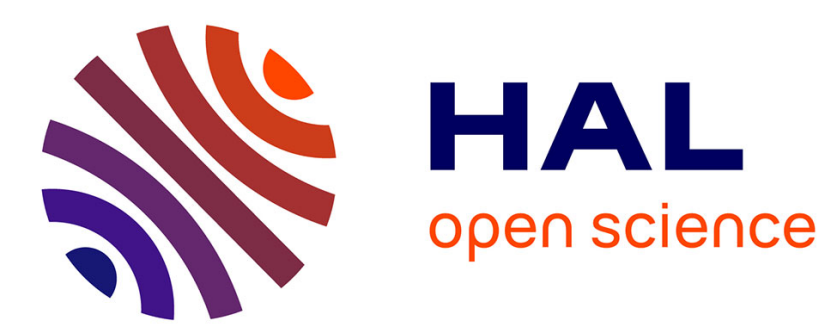

\title{
Energy Band Alignment of BiVO4 from Photoelectron Spectroscopy of Solid-state Interfaces
}

Yannick Hermans, Andreas Klein, Klaus Ellmer, Roel van de Krol, Thierry

Toupance, Wolfram Jagermann

\section{- To cite this version:}

Yannick Hermans, Andreas Klein, Klaus Ellmer, Roel van de Krol, Thierry Toupance, et al.. Energy Band Alignment of BiVO4 from Photoelectron Spectroscopy of Solid-state Interfaces. Journal of Physical Chemistry C, 2018, 122 (36), pp.20861-20870. 10.1021/acs.jpcc.8b06241 . hal-02156609

\section{HAL Id: hal-02156609 \\ https://hal.science/hal-02156609}

Submitted on 14 Jun 2019

HAL is a multi-disciplinary open access archive for the deposit and dissemination of scientific research documents, whether they are published or not. The documents may come from teaching and research institutions in France or abroad, or from public or private research centers.
L'archive ouverte pluridisciplinaire HAL, est destinée au dépôt et à la diffusion de documents scientifiques de niveau recherche, publiés ou non, émanant des établissements d'enseignement et de recherche français ou étrangers, des laboratoires publics ou privés. 


\section{Energy Band Alignment of $\mathrm{BiVO}_{4}$ from}

\section{Photoelectron Spectroscopy of Solid-state Interfaces}

Yannick Hermans, ${ }^{1,2}$ Andreas Klein, ${ }^{1}$ Klaus Ellmer, ${ }^{3}$ Roel van de Krol, ${ }^{3}$ Thierry Toupance, ${ }^{2}$ Wolfram Jagermann ${ }^{1, *}$

${ }^{1}$ Surface Science Division, Department of Materials Science, Technical University Darmstadt, D-64287 Darmstadt, Germany.

${ }^{2}$ Université de Bordeaux, Institut des Sciences Moléculaires, ISM UMR 5255 CNRS, 351 Cours de la Libération, F-33405 Talence, Cédex, France.

${ }^{3}$ Institute for Solar Fuels, Helmholtz-Zentrum Berlin für Materialien und Energie GmbH, HahnMeitner-Platz 1, Berlin 14109, Germany.

* E-mail: jaegermann@surface.tu-darmstadt.de; Phone number: +4961511620770

KEYWORDS

Metal oxide heterostructures, $\mathrm{RuO}_{2}-\mathrm{BiVO}_{4}$, ITO-BiVO 


\begin{abstract}
The interface formation and energy band alignment at interfaces between polycrystalline $\mathrm{BiVO}_{4}$ and high work function $\mathrm{RuO}_{2}$ and low work function $\mathrm{Sn}$-doped $\mathrm{In}_{2} \mathrm{O}_{3}$ (ITO) has been studied using photoelectron spectroscopy with in-situ thin film deposition of the contact materials. The Schottky barrier heights for both contact films differ by $0.85 \mathrm{eV}$, which is smaller than the difference in work function and the differences observed for other semiconducting oxides, indicating a partial Fermi level pinning. Based on the present results and the comparison with other photoelectrochemically active oxides, the differences of band alignment obtained from solid/electrolyte and from solid/solid interfaces, which can exhibit substantial differences, are discussed.
\end{abstract}




\section{INTRODUCTION}

A transition from fossil to renewable energy sources is highly needed to reduce the impact of the carbon dioxide emissions on the Earth's climate. In this regard, hydrogen can play a crucial role as renewable energy carrier and chemical reactant. A sustainable way to produce hydrogen is through water splitting, which can be achieved either by a combination of photovoltaics and subsequent water electrolysis or through direct photoelectrosynthetic processes. A direct photo(electro)chemical system would allow easy use of solar heat to enhance the electrochemical reactions and may offer cost benefits compared to a combined photovoltaic-electrolysis system. ${ }^{1}$ However, up until now, no material combination has been found that fulfills all prerequisites for efficient and stable photo(electro)chemical hydrogen production. ${ }^{2}$

The photochemical production of hydrogen by titanium dioxide $\left(\mathrm{TiO}_{2}\right)$ was first demonstrated more than 45 years ago. ${ }^{3}$ Since then, more than 130 compounds have been identified as catalysts for photo(electro)chemical oxygen evolution, hydrogen evolution or overall water splitting. ${ }^{4}$ Mostly wide band-gap semiconductors such as $\mathrm{TiO}_{2}$ and zinc oxide $(\mathrm{ZnO})$ have been studied for water splitting. However, the wide band-gap of these semiconductors only allows to absorb a minor fraction of the solar spectrum, which limits the efficiency according to the ShockleyQueisser limit. ${ }^{5}$ Several alternatives with reduced band-gaps have been proposed, i.e. iron oxide $\left(\mathrm{Fe}_{2} \mathrm{O}_{3}, 2.2 \mathrm{eV}\right)$, cuprous oxide $\left(\mathrm{Cu}_{2} \mathrm{O}, 2.0 \mathrm{eV}\right)$ and bismuth vanadate $\left(\mathrm{BiVO}_{4}, 2.4 \mathrm{eV}\right)$, which, however, do not reach sufficient photovoltage for water splitting, so that sacrificial agents or a bias have to be applied. ${ }^{6} \mathrm{BiVO}_{4}$ is promising due to its relatively good stability and its reduced band-gap, allowing to reach a theoretical solar to hydrogen efficiency of $9.2 \%{ }^{7}$ In a photoelectrochemical setup $\mathrm{BiVO}_{4}$ could be used as a photoanode for oxygen evolution in the water splitting process. However, $\mathrm{BiVO}_{4}$ based devices should be carefully structured to 
overcome the inherent slow reaction kinetics and inefficient charge carrier separation of $\mathrm{BiVO}_{4}$. The structuring strategies that have been investigated are nanostructuring, co-catalyst deposition and creation of p-n junctions. ${ }^{8-12}$ Combining these strategies with the incorporation of hexavalent impurities have allowed to achieve efficiencies approaching the theoretical efficiency of $\mathrm{BiVO}_{4}$ based devices, which require PV cells for unbiased water splitting. ${ }^{7,13}$ Current research efforts are focused on determining and quantifying the beneficial effects of heterostructuring to figure out whether surface passivation, improved reaction kinetics or enhanced charge carrier collection has the strongest influence on the efficiency of $\mathrm{BiVO}_{4} .{ }^{14,15}$

The beneficial role of heterostructures is related to the particular alignment of the energy bands at the interface. This can be estimated from the band positions before contact, ${ }^{16,17}$ which neglects the actual surface and interface structures and the possibility of Fermi level pinning, however. A more reliable approach consists in determining the band alignment and phenomena such as Fermi level pinning experimentally. However, such experiments are only performed rarely and mostly interface phenomena are just derived from the band positions before contact. The band positions before contact are commonly probed through (electrochemical) flat band potential measurements, whereby the Mott-Schottky analysis is used most often. ${ }^{18-23}$ The energy bands are then aligned with respect to the standard $\mathrm{H}^{+} / \mathrm{H}_{2}$ redox potential. ${ }^{24,25}$ From such studies, the conduction band of $\mathrm{BiVO}_{4}$ has been found to lie about $0.1 \mathrm{eV}$ below the hydrogen reduction potential. ${ }^{26}$ The alignment at the interface between two materials is then obtained by subtracting the energy level alignment with respect to the hydrogen evolution potential. This is not a direct measurement but assumes that band alignments are transitive. Up to now, this hypothesis has not been demonstrated yet for electrochemical alignments and has been proven to not be valid for 
classical semiconductors. ${ }^{27}$ Additionally, the Mott-Schottky approach is based on several assumptions which are not always met experimentally. ${ }^{28}$

To obtain direct information on heterojunctions and the transitivity of band alignment, the heterostructure formation has to be studied directly, i.e. in situ. This can be done through a combination of thin film deposition and photoelectron spectroscopy. ${ }^{29,30}$

In this report, this approach was used to analyze the interfaces of $\mathrm{BiVO}_{4}$ with tin-doped indium oxide (Sn-doped $\mathrm{In}_{2} \mathrm{O}_{3}$, ITO) and ruthenium(IV) oxide $\left(\mathrm{RuO}_{2}\right)$. The two contact materials were selected due to their strong difference in work function and their ability to form non-reactive interfaces with oxides. ${ }^{31,32}$ Additionally, $\mathrm{RuO}_{2}$ has been identified as one of the most efficient stand-alone electrocatalysts for the oxygen evolution reaction. ${ }^{33}$ For $\mathrm{BiVO}_{4}, \mathrm{RuO}_{2}$ has been successfully used as a co-catalyst for the thiophene photooxidation and water oxidation in a Zscheme system. ${ }^{34,35}$ ITO on the other side is a transparent conductive oxide since it has a high

conductivity combined with a high optical transparency. ${ }^{36,37}$ Because of these properties it can be implemented as a transparent electrode in photovoltaic devices ${ }^{38,39}$ or photoelectrochemical cells ${ }^{40}$. In $\mathrm{BiVO}_{4}$ photoanodes both ITO and fluorine-doped $\mathrm{SnO}_{2}$ (FTO) have been used as back contacts. $^{7,13}$

\section{MATERIALS AND METHODS}

\subsection{Synthesis of $\mathrm{BiVO}_{4}$ thin films and $\mathrm{Mo}_{\mathrm{BiVO}}$ single crystals}

The polycrystalline $\mathrm{BiVO}_{4}$ thin films were prepared by reactive magnetron sputtering using a home-built magnetron sputtering system equipped with a load lock. ${ }^{41}$ A co-sputtering setup was used with two separate 2 inches diameter metallic Bi (99.9\%) and V (99.99\%) targets, inclined by $30^{\circ}$ to each other and focused onto a soda lime glass substrate with a size of $22 \times 22 \mathrm{~mm}^{2}$. The glass substrates were coated with a highly conductive and transparent $\mathrm{SnO} 2: \mathrm{F}$ film, which 
served as back contact during the XPS measurements. The sputtering atmosphere was an $\mathrm{Ar} / \mathrm{O}_{2}$ gas mixture $\left(20 \% \mathrm{O}_{2}\right)$ at a total sputtering pressure of $1 \mathrm{~Pa}$. The DC power at the $\mathrm{Bi}$ target was about 20-30 W, while the DC power at the V target was $450 \mathrm{~W}$. While the V-target-to-substrate distance was $6 \mathrm{~cm}$, the Bi- target-to-substrate distance was $12 \mathrm{~cm}$. Since no rotation stage was used during sputtering, every sample contained a $\mathrm{Bi} / \mathrm{V}$ compositional gradient along the sample width. After sputtering, the films were annealed in a muffle furnace at $500{ }^{\circ} \mathrm{C}$ in air for 2 hours, using a temperature ramp of $10 \mathrm{~K} / \mathrm{min}$.

A molybdenum doped $\mathrm{BiVO}_{4}$ single crystal $\left(\mathrm{Mo}: \mathrm{BiVO}_{4}\right)$ with an exposed (010) surface was used as a reference for XPS and Raman measurements. The single crystal was grown through the Czochralski method with RF induction heating and automatic control of the crystal diameter. ${ }^{42}$ The amount of molybdenum oxide in the crucible was adjusted to reach a $1 \%$ substitution of vanadium.

Raman spectra were recorded with a Raman spectrometer (LabRAM HR) using an Argon laser $(488 \mathrm{~nm})$ as excitation source with a laser power on the sample of approximately $10 \mathrm{~mW}$ and a 10x objective generating a spot size of approximately $2 \mu \mathrm{m}$.

\subsection{Interface formation and analysis}

Surface analysis and interface experiments were performed at the Darmstadt Integrated System for Materials research (DAISY-MAT) ${ }^{31,43}$ This setup is a combination of several thin film deposition chambers, including ALD, CVD and sputtering, with a Physical Electronics PHI 5700 multi-technique surface analysis system, used for recording Ultraviolet (UPS) and X-ray (XPS) photoelectron spectra. Transferring the samples between the different compartments is possible without breaking the ultrahigh vacuum (UHV) conditions, avoiding contamination in between deposition and analysis. XPS measurements were performed using Al $\mathrm{K} \alpha$ radiation with an 
energy resolution of approximately $400 \mathrm{meV}$, determined from the Gaussian broadening of the Fermi edge of a sputter cleaned Ag sample. The Fermi edge of the silver sample was also used to calibrate the binding energies of all measured samples. Background subtraction was performed with a Tougaard function for the $\mathrm{Bi} 4 \mathrm{f}$ peaks and Shirley functions for $\mathrm{V} 2 \mathrm{p}_{3 / 2}$ and $\mathrm{O} 1 \mathrm{~s}$ peaks. To determine the V/Bi surface ratio with XPS, peak areas of the Bi $4 \mathrm{f}$ and $\mathrm{V} 2 \mathrm{p}_{3 / 2}$ background corrected peaks were integrated and then corrected using machine specific sensitivity factors. ${ }^{44}$ Ultraviolet photoelectron spectra were measured using He I radiation.

To study the band alignment of $\mathrm{BiVO}_{4}$ in contact with a specific compound, the following interface experiments were performed. First, the $\mathrm{BiVO}_{4}$ substrates were cleaned with acetone in an ultrasonic bath for 15 minutes, then rinsed with ethanol and water and subsequently dried using compressed air. The substrates were then entered through a load lock into the DAISYMAT. Remaining organic compounds were removed from the substrate surface with an oxygen plasma treatment of 15 minutes. Then the interface experiments were performed, whereby the target compound was stepwise sputtered onto the $\mathrm{BiVO}_{4}$ substrate, which was held at room temperature during deposition. After each deposition step, core level binding energies of $\mathrm{BiVO}_{4}$ and the sputtered compound were measured through XPS. Additionally, UPS was performed on the $\mathrm{BiVO}_{4}$ substrate and on the deposited film to measure the secondary electron cutoff, which was used to obtain the work functions of both materials. The deposition parameters of the investigated contact materials, $\mathrm{RuO}_{2}$ and ITO, can be found in Table $1 . \mathrm{RuO}_{2}$ was reactively sputtered from a metallic Ru target and ITO was sputtered from a ceramic ITO target. All targets had a diameter of 2 inches. 
Table 1. Magnetron Sputtering Deposition Parameters for $\mathrm{RuO}_{2}$ and ITO Thin Films ${ }^{\mathrm{a}}$

\begin{tabular}{ccc}
\hline & $\mathrm{RuO}_{2}$ & $\mathrm{ITO}$ \\
\hline $\mathrm{T}_{\text {sub }}\left({ }^{\circ} \mathrm{C}\right)$ & $\mathrm{RT}$ & $\mathrm{RT}$ \\
$\mathrm{P}_{\mathrm{r}}(\mathrm{Pa})$ & 1 & 0.5 \\
$\mathrm{O}_{2} / \mathrm{Ar}$ ratio $(\%)$ & 7.5 & 0 \\
$\mathrm{P}(\mathrm{W})$ & $10(\mathrm{DC})$ & $25(\mathrm{RF})$ \\
Flux $(\mathrm{sccm})$ & 10 & 6.6 \\
$\mathrm{~d}(\mathrm{~cm})$ & 9.1 & 9.6 \\
$\mathrm{R}\left(\mathrm{nm} \cdot \mathrm{min}^{-1}\right)$ & 3 & 5
\end{tabular}

${ }^{\mathrm{a}} \mathrm{T}_{\text {sub }}$ is substrate temperature, $\mathrm{RT}$ is room temperature, $\mathrm{P}_{\mathrm{r}}$ stands for pressure, $\mathrm{P}$ is the power applied to the sputter target, $\mathrm{d}$ is the target-to-substrate distance and $\mathrm{R}$ stands for the deposition rate of the film.

\section{RESULTS}

\subsection{Substrate analysis}

Due to the absence of sample rotation during $\mathrm{BiVO}_{4}$ thin film co-sputtering, a lateral variation in the $\mathrm{Bi} / \mathrm{V}$ composition is observed. Hereby, Raman spectroscopy was used to identify the phases along the $\mathrm{Bi} / \mathrm{V}$ gradient. Raman spectra at specific positions along the lateral $\mathrm{Bi} / \mathrm{V}$ gradient are shown in Figure 1. Along the entire gradient, monoclinic $\mathrm{BiVO}_{4}$ is observed as the main phase with characteristic resonances at $127,213,328,370,712,828 \mathrm{~cm}^{-1} \cdot{ }^{45}$ Features at 828 and $712 \mathrm{~cm}^{-1}$ can be attributed to antisymmetric and symmetric stretching vibration modes of the $\mathrm{VO}_{4}$ tetrahedra. ${ }^{46}$ The bending modes of the $\mathrm{VO}_{4}$ tetrahedra are the cause of the resonances at 370 and $328 \mathrm{~cm}^{-1}$ whereas the peaks at 213 and $147 \mathrm{~cm}^{-1}$ correspond to external modes ${ }^{47}$ and crystal lattice vibration of $\mathrm{BiVO}_{4}{ }^{46}$ In the $\mathrm{V}$ rich part of the film additional peaks appear at 147 , 
287, 531, $997 \mathrm{~cm}^{-1}$. These peaks correspond to the frequencies of the Raman active modes of orthorhombic $\mathrm{V}_{2} \mathrm{O}_{5}{ }^{45,48}$ Towards the middle of the film, at $10 \mathrm{~mm}$ distance from the Bi edge, no extra peaks can be observed anymore, which indicates that no

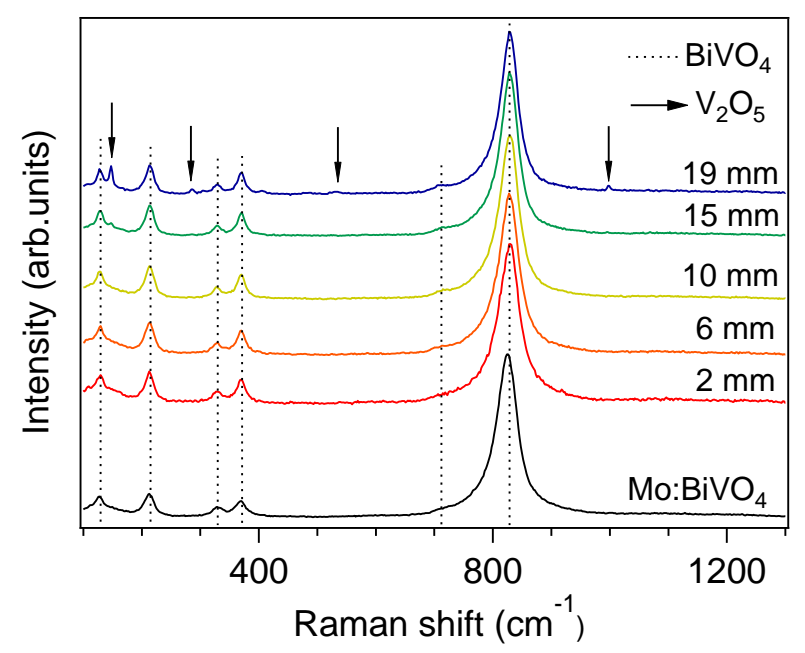

Figure 1. Raman spectra of the $\mathrm{BiVO}_{4}$ gradient thin film and of a Mo:BiVO 4 single crystal. The Raman spectra of the gradient thin film were measured at specific distances from the Bi rich edge.

other phases besides monoclinic $\mathrm{BiVO}_{4}$ are present. The amount of noise increases while moving further to the Bi rich edge, making it difficult to distinguish any other phases besides monoclinic $\mathrm{BiVO}_{4}$.

The surface composition and electronic properties of the $\mathrm{BiVO}_{4}$ gradient thin films were also studied by photoelectron spectroscopy. In Figure 2 X-ray photoelectron survey spectra were recorded with a spot size of $1 \mathrm{~mm}^{2}$ along the $\mathrm{Bi} / \mathrm{V}$ gradient. The main elements present at the film surface are $\mathrm{Bi}, \mathrm{V}$ and $\mathrm{O}$ since the $\mathrm{Bi} 4 \mathrm{~d}, \mathrm{Bi} 4 \mathrm{f}, \mathrm{Bi} 5 \mathrm{~d}, \mathrm{~V} 2 \mathrm{p}, \mathrm{V} 3 \mathrm{~s}, \mathrm{~V} 3 \mathrm{~d}$ and $\mathrm{O} 1 \mathrm{~s}$ core level emissions are detected at every measurement position. Additionally, at some positions a weak signal of the Sn3d core level was registered. The detection of tin is due to small holes between 
the grains of the $\mathrm{BiVO}_{4}$ film that form during coalescence of the grains at elevated temperatures, exposing some of the underlying FTO layer. Due to an oxygen plasma treatment, used to remove the carbon contamination layer, no core level emissions corresponding to carbon were detected (Figure S1). Besides the removal of carbon from the surface the oxygen plasma resulted in slight binding energy shifts but did not change the chemical composition of the film as can be noticed form the more detailed core level spectra of Bi4f, V2 $\mathrm{p}_{3 / 2}$ and O1s in Figure S2.

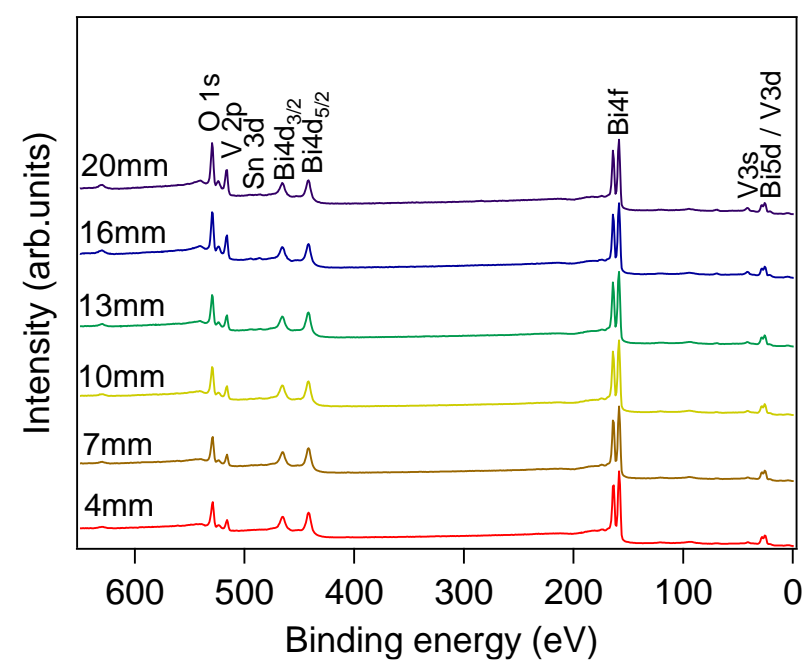

Figure 2. Survey XP spectra of the gradient $\mathrm{BiVO}_{4}$ thin film at specific distances from the $\mathrm{Bi}$ rich edge.

More detailed core level spectra were recorded for Bi4f, V2 $\mathrm{p}_{3 / 2}$ and O1s (Figure 3). The Bi4f $\mathrm{f}_{7 / 2}$ core level binding energy is around $159.0 \mathrm{eV}$, which matches to $\mathrm{Bi}^{3+}$ in $\mathrm{BiVO}_{4}$ and the $\mathrm{V}_{2} \mathrm{p}_{3 / 2}$ core level position around $516.7 \mathrm{eV}$ is typical for $\mathrm{V}^{5+}$ in $\mathrm{BiVO}_{4}{ }^{45}$ All core level binding energies shift towards higher energies with increasing $\mathrm{V}$ content in the film. This increase is partly due to a changing Fermi energy since Bi4f and O1s binding energies both shift similarly by $0.18 \mathrm{eV}$. However, the core level of $\mathrm{V} 2 \mathrm{p}_{3 / 2}$, shifts $0.30 \mathrm{eV}$ up in energy, which is slightly different from the other core level shifts and is probably due to a change in surface chemistry. The chemical change can be due to the presence of $\mathrm{V}_{2} \mathrm{O}_{5}$, which was detected with Raman spectroscopy. 

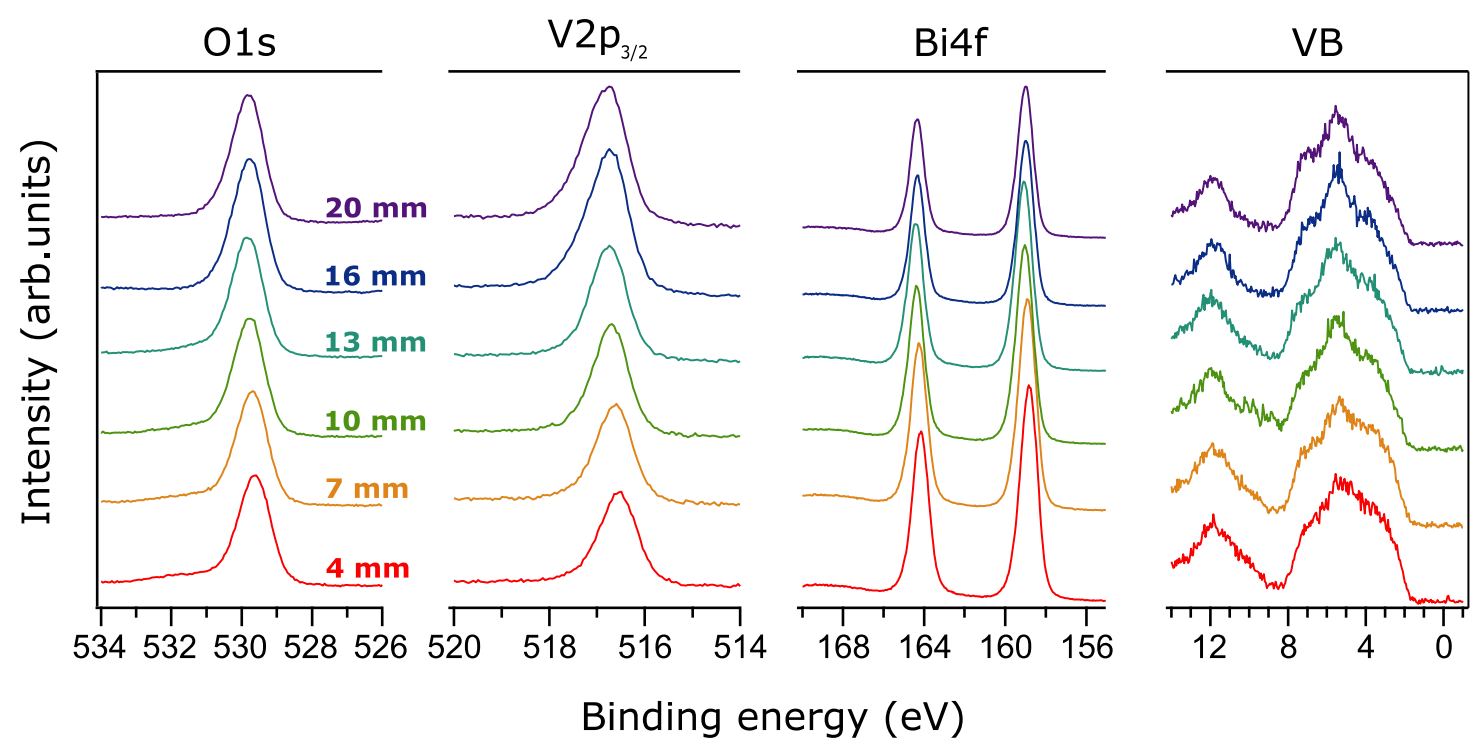

Figure 3. Bi4f, V2 $\mathrm{p}_{3 / 2}$, O1s core level and valence band $\mathrm{XP}$ spectra of the gradient $\mathrm{BiVO}_{4}$ thin film at specific distances from the Bi rich edge.

The core level spectra were also used to determine the surface $\mathrm{V} / \mathrm{Bi}$ ratio by integrating the peak areas of the Bi4f and $\mathrm{V} 2 \mathrm{p}_{3 / 2}$ core levels and multiplying the integrated areas by the respective tabulated sensitivity factors. ${ }^{44}$ In Figure 4 the V/Bi ratios are shown as a function of the distance to the Bi rich edge of the film. Preferably, interface experiments are performed on stoichiometric $\mathrm{BiVO}_{4}$ and for pure stoichiometric $\mathrm{BiVO}_{4}$ a $\mathrm{V} / \mathrm{Bi}$ ratio of 1:1 would be expected. However, there is no position on the film where this ratio is observed. After $15 \mathrm{~mm}$, there is a sudden increase to a $\mathrm{V} / \mathrm{Bi}$ ratio of 1.4, indicating that the surface is $\mathrm{V}$ rich at this position, which is probably due to the presence of the vanadium oxide phase, which was detected by Raman spectroscopy. From $4 \mathrm{~mm}$ to $13 \mathrm{~mm}$ the $\mathrm{V} / \mathrm{Bi}$ ratio increases almost linearly from 0.5 to 0.76 . In this region the surface, thus, seems Bi rich. 


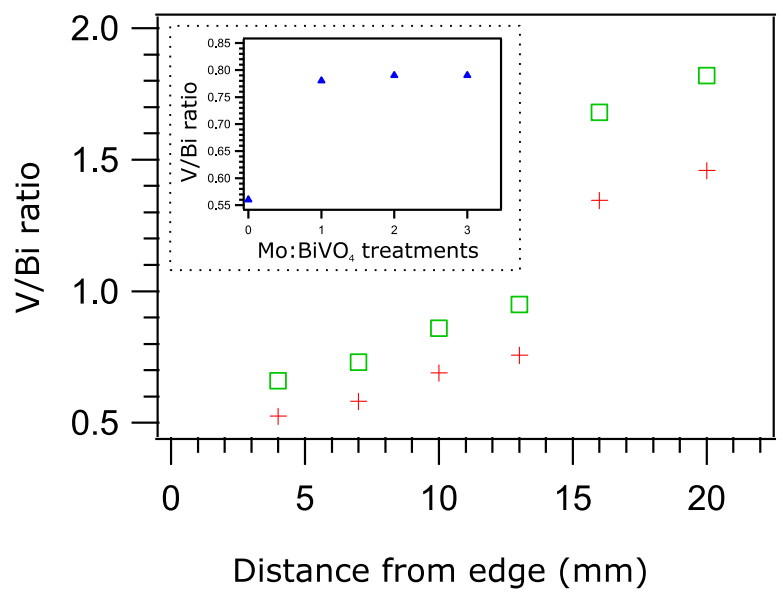

Figure 4. XPS V/Bi ratio: using the tabulated sensitivity factors (red crosses) and after applying the correction factor determined from the (010) exposed $\mathrm{Mo:BiVO} 4$ single crystal (green squares). In the inset the $\mathrm{V} / \mathrm{Bi}$ ratio of the $(010) \mathrm{Mo}: \mathrm{BiVO}_{4}$ single crystal is shown after various treatments: 0: no treatment; 1: polished; 2: polished +15 min $\mathrm{O}_{2}$ plasma; 3: $2^{\text {nd }}$ time polished + 15 min $\mathrm{O}_{2}$ plasma.

However, in Raman no additional Bi rich phase was found so it is not clear where this high off-stoichiometry comes from. Possibly, the calculated V/Bi ratios are different from the real $\mathrm{V} / \mathrm{Bi}$ ratios, because the sensitivity factors used in the calculations do not accurately correct for the difference in detection probability of $\mathrm{Bi} 4 \mathrm{f}$ and $\mathrm{V} 2 \mathrm{p}_{3 / 2}$ core electrons. Instrument specific sensitivity factors were used, but it could be that they are not specific for $\mathrm{BiVO}_{4}$. Improper determination of stoichiometry has also been observed at the same system, whenever large cations are involved, as for example for $\mathrm{CdS}^{49}$

In order to provide more information about the stoichiometry determination, a monoclinic $1 \%$ Mo doped $\mathrm{BiVO}_{4}$ single crystal with a (010) exposed crystal facet was used as a reference to find the sensitivity factors that correctly predict the detection probability of Bi4f and $\mathrm{V} 2 \mathrm{p}_{3 / 2}$ core electrons and to eventually determine more accurate $\mathrm{V} / \mathrm{Bi}$ ratios. The Raman spectrum of the Mo:BiVO 4 single crystal in Figure 1 confirms that it is monoclinic $\mathrm{BiVO}_{4}$ because the observed peaks (at 127, 213, 328, 370, 712, $828 \mathrm{~cm}^{-1}$ ) correspond to the Raman active modes expected for monoclinic $\mathrm{BiVO}_{4}{ }^{45}$ 

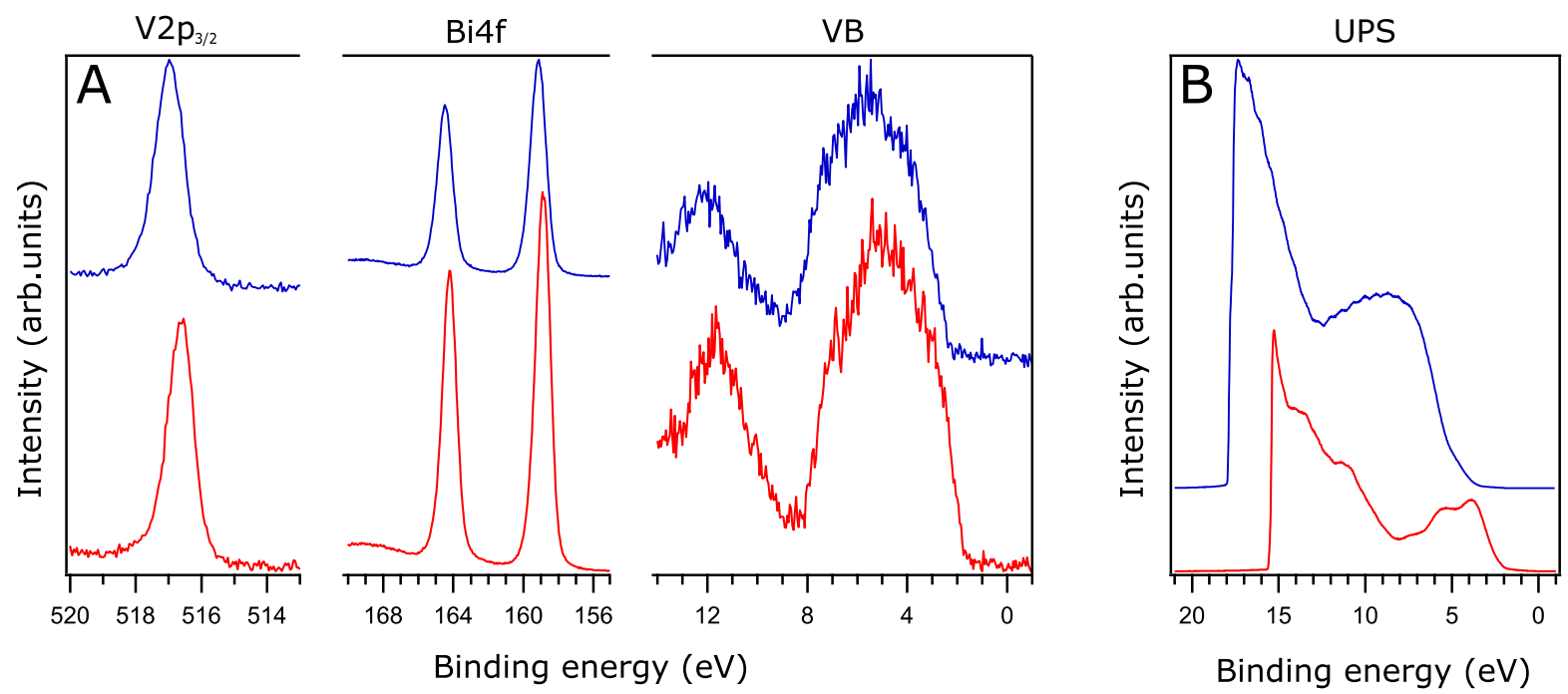

Figure 5. A) V2 $\mathrm{p}_{3 / 2}$, Bi4f core level and valence band XP spectra and B) UP spectra of the gradient $\mathrm{BiVO}_{4}$ thin film at $13 \mathrm{~mm}$ from the $\mathrm{Bi}$ rich edge (red) and the polished (010) surface of the $\mathrm{Mo}: \mathrm{BiVO}_{4}$ single crystal (blue). Both samples were cleaned by sputtering with an oxygen plasma.

The single crystal was polished along the (010) surface to expose the internal structure and sputter cleaned with an oxygen plasma for 15 minutes. In Figure $5 \mathrm{~A}$ the Bi4f, V2 $\mathrm{p}_{3 / 2}$ and valence band X-ray photoelectron spectra of the polished and sputter cleaned Mo:BiVO 4 single crystal are shown as well as those of a sputter cleaned gradient $\mathrm{BiVO}_{4}$ thin film at $13 \mathrm{~mm}$ from the $\mathrm{Bi}$ rich edge. The Bi4f and V2 $\mathrm{p}_{3 / 2}$ spectra of the single crystal are shifted by about $0.2 \mathrm{eV}$ towards higher binding energies and its $\mathrm{E}_{\mathrm{f}}-\mathrm{E}_{\mathrm{VB}}$ lies at $2.2 \mathrm{eV}$, compared to an $\mathrm{E}_{\mathrm{f}}-\mathrm{E}_{\mathrm{VBM}} 1.8 \mathrm{eV}$ for the gradient thin film. The shift towards higher binding energies could be due to a shift in the Fermi level position, originating from the Mo doping in the single crystal. However, due to the low conductivity of $\mathrm{BiVO}_{4}$ the binding energy shift in the XP spectra could also be due to surface charging. The effect of surface charging can be clearly seen in the UP spectra of the

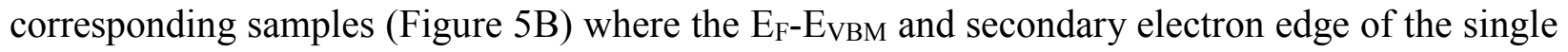
crystal are shifted by about $2.5 \mathrm{eV}$ towards higher energies, a shift too large to be explained by doping. The eventual surface charging has, however, no impact on the XP core level peak areas, 
so that the $\mathrm{V} / \mathrm{Bi}$ ratio could still be determined from the integrated $\mathrm{Bi}_{4} \mathrm{f}_{7 / 2}$ and $\mathrm{V} 2 \mathrm{p}_{3 / 2}$ peak areas (inset Figure 4). After polishing and $\mathrm{O}_{2}$ plasma exposure, a V/Bi ratio of 0.79 was obtained using the standard instrument sensitivity factors. This V/Bi ratio differs largely from the expected ratio of 0.99 , considering that $1 \%$ of the vanadium lattice sites are substituted by molybdenum. Thus, the $\mathrm{V} / \mathrm{Bi}$ surface ratios calculated from the tabulated sensitivity factors are incorrect and should be adjusted by a correction factor. A correction factor of 1.25 can be calculated by dividing the expected $\mathrm{V} / \mathrm{Bi}$ ratio of 0.99 through the sensitivity factor determined ratio of 0.79 . The corrected $\mathrm{V} / \mathrm{Bi}$ ratios for the gradient $\mathrm{BiVO}_{4}$ thin films are included in Figure 4. A V/Bi ratio of 0.95 is obtained at $13 \mathrm{~mm}$ from the $\mathrm{Bi}$ edge, which is closer to stoichiometric $\mathrm{BiVO}_{4}$. The bulk $\mathrm{V} / \mathrm{Bi}$ ratio was determined through EDS and showed that at $11 \mathrm{~mm}$ distance a V/Bi ratio of 1.02 was obtained, thus very similar to the XPS result (Figure S3).

From Raman, EDS and XPS measurements it can be concluded that at $13 \mathrm{~mm}$ distance from the $\mathrm{Bi}$ rich edge the gradient film consists of single phase monoclinic $\mathrm{BiVO}_{4}$. Therefore, this position was used to interpret interface experiments between monoclinic polycrystalline $\mathrm{BiVO}_{4}$ and various contact layers. During interface experiments all photoelectron spectra were, thus, measured at $13 \mathrm{~mm}$ distance from the Bi rich edge.

\subsection{Interface analysis}

First, the interface between $\mathrm{BiVO}_{4}$ and $\mathrm{RuO}_{2}$ was studied. $\mathrm{RuO}_{2}$ films with increasing thickness were subsequently sputtered on a $\mathrm{BiVO}_{4}$ thin film and the changes during the $\mathrm{BiVO}_{4} / \mathrm{RuO}_{2}$ interface formation were probed through photoelectron spectroscopy. The X-ray photoelectron spectra of Bi4f, V2p $3 / 2, \mathrm{O} 1 \mathrm{~s}$, Ru3d core levels and valence band are shown in Figure 6 after each deposition step of $\mathrm{RuO}_{2}$. The increasing thickness of $\mathrm{RuO}_{2}$ can be monitored as the intensity of the Ru3d core level peak increases while the intensity of Bi4f and V2p $3 / 2$ core 
levels decreases after each deposition step. To investigate how the energy bands between semiconducting $\mathrm{BiVO}_{4}$ and metallic $\mathrm{RuO}_{2}$ align, the change in $\mathrm{VB}$ maximum of $\mathrm{BiVO}_{4}$ should be followed.

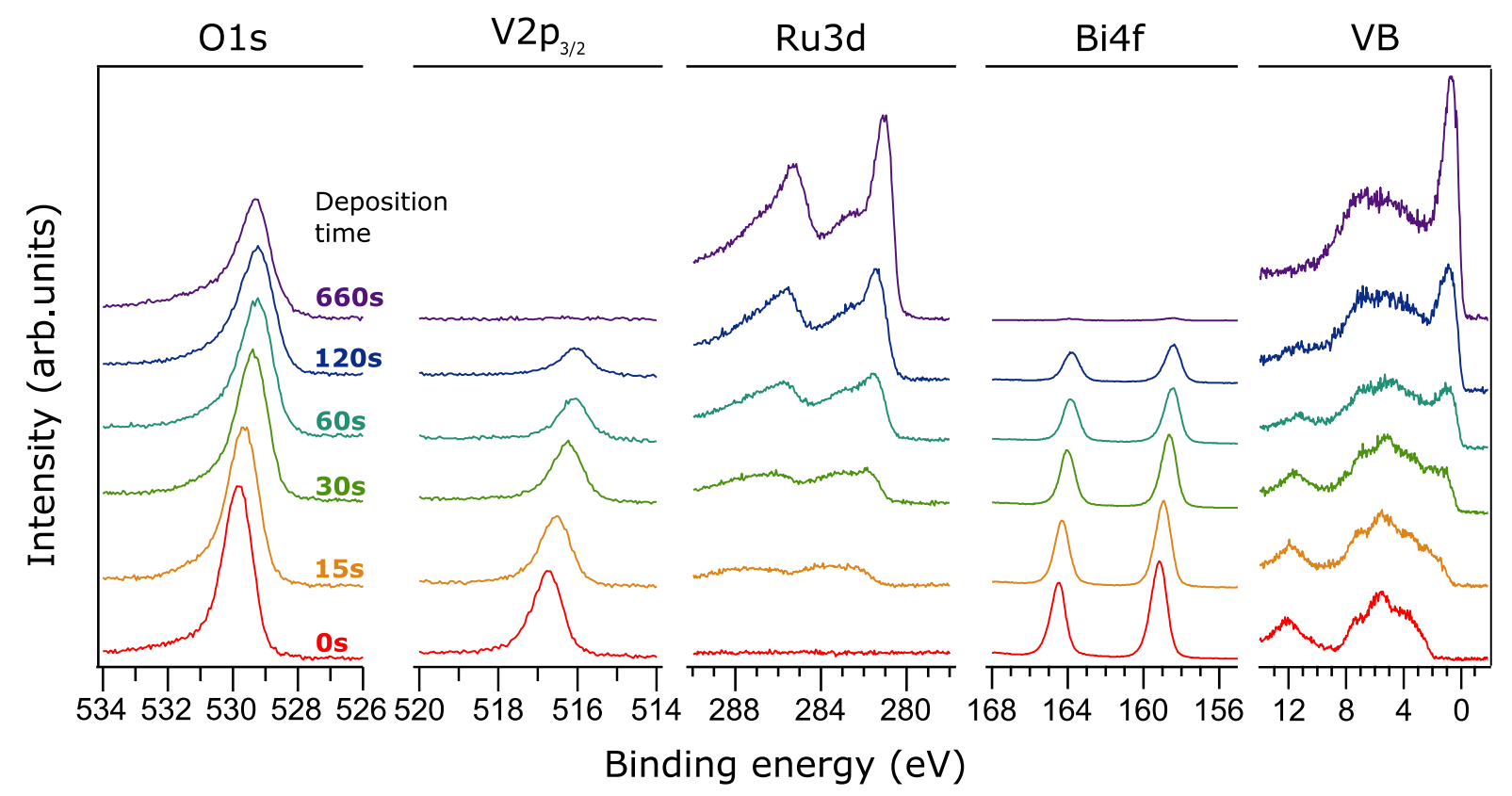

Figure 6. O1s, V2p $3 / 2$, Ru3d, Bi4f core level and valence band XP spectra for the $\mathrm{BiVO}_{4} / \mathrm{RuO}_{2}$ interface. $\mathrm{RuO}_{2}$ deposition times are denoted at the $\mathrm{O} 1 \mathrm{~s}$ spectra.

However, following this change is not feasible due to superposition of $\mathrm{BiVO}_{4}$ and $\mathrm{RuO}_{2}$ valence bands. Therefore, the change in substrate valence band maximum (VBM) has to be evaluated from the change of the substrate core level energies. This method is commonly referred to as the Kraut method. ${ }^{50}$ The Bi4f and V2p $\mathrm{p}_{3 / 2}$ core level spectra shift gradually to lower binding energies. As both $\mathrm{Bi}_{4} \mathrm{f}_{7 / 2}$ and $\mathrm{V} 2 \mathrm{p}_{3 / 2}$ core levels have a similar shift of $0.71 \mathrm{eV}$, the shift can be attributed to a change of Fermi level at the substrate surface due to $\mathrm{RuO}_{2}$ induced band bending.

Next, the interface between ITO and $\mathrm{BiVO}_{4}$ was investigated. The core level spectra of Bi4f, $\mathrm{V} 2 \mathrm{p}_{3 / 2}, \mathrm{O} 1 \mathrm{~s}, \mathrm{In} 3 \mathrm{~d}_{5 / 2}$ and valence bands for the stepwise sputter deposition of ITO on $\mathrm{BiVO}_{4}$ are 
displayed in Figure 7. As the In3d core level intensity increases, the Bi4f, V2p3/2 core level intensity drops. The O1s core level intensity stays approximately constant with increasing ITO thickness. In contrast to the $\mathrm{RuO}_{2}$ deposition, the $\mathrm{Bi} 4 \mathrm{f}$ and $\mathrm{V} 2 \mathrm{p}_{3 / 2}$ peak maxima shift to higher binding energies after ITO deposition. This is expected since the work function of ITO is substantially lower than the work function of $\mathrm{RuO}_{2}$.

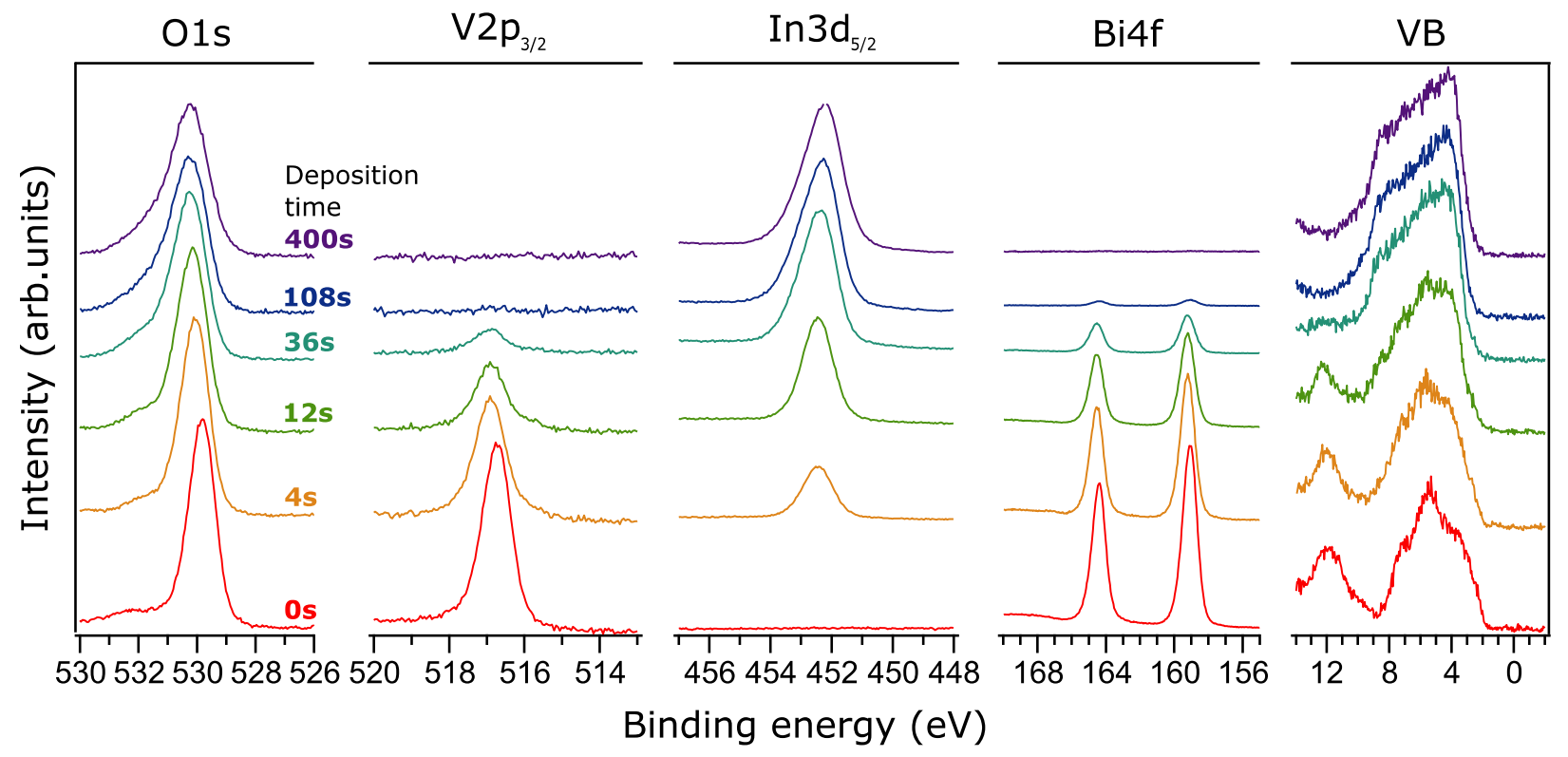

Figure 7. O1s, V2 $\mathrm{p}_{3 / 2}, \mathrm{In} 3 \mathrm{~d}_{5 / 2}, \mathrm{Bi} 4 \mathrm{f}$ core level and valence band $\mathrm{XP}$ spectra for $\mathrm{BiVO}_{4} / \mathrm{ITO}$ interface. ITO deposition times are denoted in the O1s spectra.

After the first deposition step the peak maxima of both $\mathrm{V} 2 \mathrm{p}_{3 / 2}$ and $\mathrm{Bi}_{7 / 2}$ shift by approximately $0.16 \mathrm{eV}$. Thereafter, both peak maxima stay around the same value with increasing film thickness. Since both $\mathrm{V} 2 \mathrm{p}_{3 / 2}$ and $B i 4 \mathrm{f}_{7 / 2}$ shift in the same way, the shift can be interpreted as a shift caused by downward band bending.

Combining the information from the interface experiments with the determined work functions from ultraviolet photoelectron spectra (Figure 8: 5.6-5.7 eV for $\mathrm{BiVO}_{4}, 6.5 \mathrm{eV}$ for $\mathrm{RuO}_{2}$ and 4.4 $\mathrm{eV}$ for ITO) allow to construct complete energy band diagrams for the $\mathrm{BiVO} / \mathrm{RuO}_{2}$ and 
$\mathrm{BiVO}_{4} / \mathrm{ITO}$ interfaces (Figure 9). The band-gap of $\mathrm{BiVO}_{4}, 2.4 \mathrm{eV}$, and from ITO, $2.8 \mathrm{eV}$, were taken from literature..$^{51,52}$

The energy bands displayed in Figure 9 include the vacuum energy levels of the materials, which are derived from work function measurements using UPS. According to the measured work functions, the vacuum energies of $\mathrm{BiVO}_{4}$ and $\mathrm{RuO}_{2}$ are aligned while there is a dipole potential

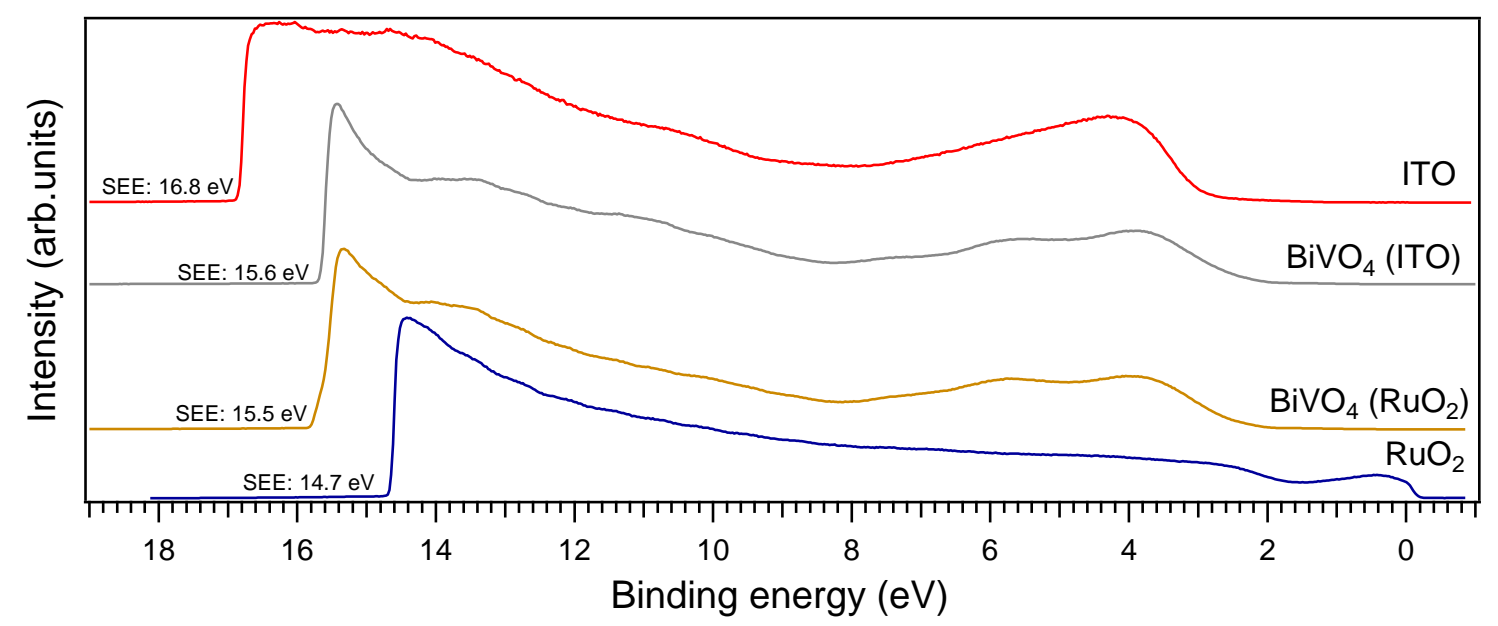

Figure 8. UP spectra (He I excitation) of $\mathrm{RuO}_{2}$ (blue), $\mathrm{BiVO}_{4}$ (from $\mathrm{RuO}_{2}$ interface experiment) (gold), $\mathrm{BiVO}_{4}$ (from ITO interface experiment), and ITO (red) with secondary electron edge (SEE) values. 

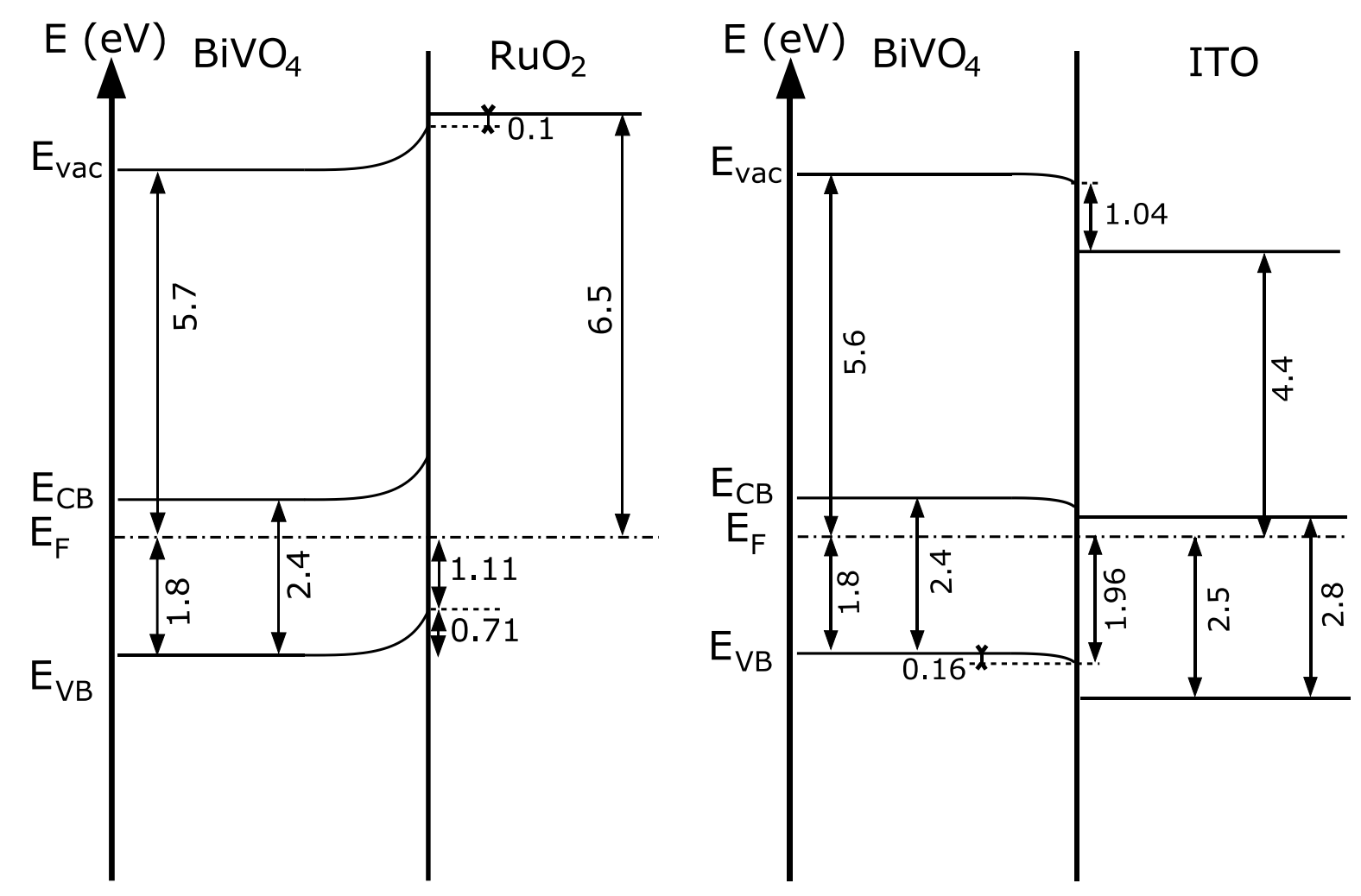

Figure 9. Energy band diagrams of the $\mathrm{BiVO}_{4} / \mathrm{RuO}_{2}$ and $\mathrm{BiVO}_{4} / \mathrm{ITO}$ interface derived from the combination of X-ray and ultraviolet photoelectron spectroscopy. The Fermi level, band-gap, band bending and barrier heights are shown, whereby all energy values are denoted in $\mathrm{eV}$. The band-gaps of $\mathrm{BiVO}_{4}$ and ITO were taken from literature. ${ }^{51,52}$.

step of about $1 \mathrm{eV}$ between $\mathrm{BiVO}_{4}$ and ITO. The latter might be caused by a high density of interface states in the $\mathrm{BiVO}_{4}$, which pin the Fermi energy.

It is known, however, that semiconducting oxides often exhibit a huge dipole potential step upon forming a Schottky barrier with $\mathrm{RuO}_{2} \cdot{ }^{31}$ These Schottky barrier heights would imply a work function of $\mathrm{RuO}_{2}$ of about $5.6 \mathrm{eV}$; if this work function would be considered instead of the work function of $6.5 \mathrm{eV}$ measured in Figure 8, a similar dipole potential step would be present at both the $\mathrm{BiVO}_{4} / \mathrm{RuO}_{2}$ and $\mathrm{BiVO}_{4} / \mathrm{ITO}$ interfaces. The dipole potential step is possibly due to the oxygen plasma treatment of the $\mathrm{BiVO}_{4}$ surface, which could lead to a more negatively charged surface compared to the ITO or $\mathrm{RuO}_{2}$ contact layer. The difference in Fermi energy at the 
$\mathrm{BiVO}_{4} / \mathrm{RuO}_{2}$ and $\mathrm{BiVO}_{4} / \mathrm{ITO}$ interfaces amounts to $0.85 \mathrm{eV}\left(1.11 \mathrm{vs} 1.96 \mathrm{eV}\right.$ for $\mathrm{E}_{\mathrm{F}}-\mathrm{E}_{\mathrm{VBM}}$, respectively, see Figure 9.

\section{DISCUSSION}

Capacitance-derived flat-band potential measurements from Mott-Schottky plots give, next to information on the kinetics and energetics of the semiconductor-liquid junctions, information on the location of the band positions with respect to the reference electrode. Such measurements were often performed in the early days of semiconductor electrochemistry (1970s - 1980s), mostly on defined surfaces of single crystals. These were used to align the commonly studied semiconductor electrodes relative to the $\mathrm{H}^{+} / \mathrm{H}_{2}$ redox potential. ${ }^{20-23}$ By assuming transitivity of band alignment this provides a comparison of band edge energies of the different photoelectrodes. The energy band alignment of different oxides inferred from such studies is shown in Figure 10.

From the electrochemical alignment of the energy bands, which positions the valence and conduction band energies relative to the $\mathrm{H}^{+} / \mathrm{H}_{2}$ redox potential and which is established in literature, ${ }^{20,22,53}$ the relative alignment between two semiconducting oxides can be directly extracted by assuming transitivity. In principle, the same can be achieved using the Fermi level position at the interfaces of the oxides with the same metal, also assuming transitivity. ${ }^{54}$ The interface experiments with $\mathrm{RuO}_{2}$ and ITO described in this article can, in principle, both be used 


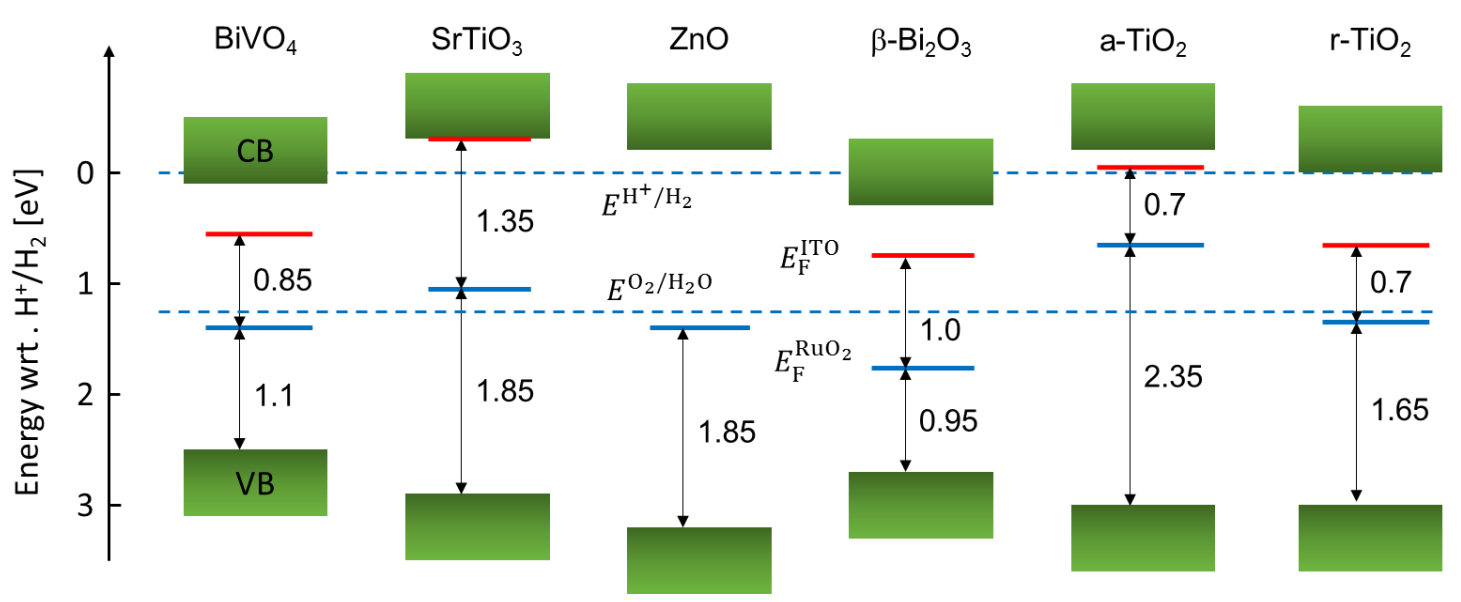

Figure 10. Conduction band and valence band alignment of a series of semiconductor oxides relative to the $\mathrm{H}^{+} / \mathrm{H}_{2}$ standard redox potential and the Fermi level position of these oxides at the interfaces with $\mathrm{RuO}_{2}$ (blue) and ITO (red).

to compare the band edge energies. ${ }^{32,55}$ Transitivity of band alignment is, however, not necessarily valid when Fermi level pinning is involved in interface formation, as this affects the measured Fermi level positions. ${ }^{31,43,56,57}$ In the extreme case of pinning, known as Bardeen limit, the Fermi level at an interface becomes independent on metal work function. In such a case, the Fermi level at the interfaces with $\mathrm{RuO}_{2}$ and ITO would be identical. This is definitely not the case, as evidenced by Figure 10. Additionally, the band edge positions or dipole layer at the interface may drift due to adsorbates as well as ionic surface terminations. Such offsets may be expected, especially for semiconductor/electrolyte interfaces, but they have hardly been studied yet in a systematic manner. ${ }^{30}$

For classical semiconductors, Fermi level pinning might be induced by virtual gap states ${ }^{54,58}$,or by deposition-induced defects. ${ }^{59}$ The latter are almost always observed during deposition of elementary metals on clean oxide surfaces, ${ }^{31,60,61}$ but can be avoided by contact formation with conducting metal oxides, depending on the applied deposition parameters. ${ }^{31}$ The Fermi levels observed at contacts of $\mathrm{BiVO}_{4}$ (this work) and other oxides with $\mathrm{RuO}_{2}$ (high work function) and ITO (low work function) are included in Figure 10. In the present case, the variation of Fermi 
level position at the interfaces of $\mathrm{BiVO}_{4}$ amounts to $0.85 \mathrm{eV}$. This variation is slightly higher than observed for rutile and anatase $\mathrm{TiO}_{2},{ }^{62}$ but lower than the variation observed for $\mathrm{SrTiO}_{3} \cdot{ }^{31,63,64}$ The experimentally observed variation of Fermi level positions therefore indicates that the Fermi level at the studied $\mathrm{BiVO}_{4}$ interfaces can vary but not as much as for other oxides. Whether this reduced splitting of the Fermi level is caused by an insufficient upward shift of $E_{F}$ at the $\mathrm{BiVO}_{4} / \mathrm{ITO}$ interface or by an insufficient downward shift of $\mathrm{E}_{\mathrm{F}}$ at the $\mathrm{BiVO}_{4} / \mathrm{RuO}_{2}$ interface or both cannot be discriminated from the present experiments. More extended studies of the variation of the Fermi energy using different sample treatments and interface formation would be required to resolve this. However, the partial Fermi level pinning will most likely have no severe effect on the efficiency of $\mathrm{BiVO}_{4}$ photoanodes, since an upwards band bending of 0.71 $\mathrm{eV}$ was observed for the contact between $\mathrm{BiVO}_{4}$ and the high work function material, $\mathrm{RuO}_{2}$. The possibility of high upwards band bending makes that holes can be efficiently separated from electrons to partake in water oxidation at the $\mathrm{BiVO}_{4}$ photoanode surface.

In the case of $(\mathrm{Ba}, \mathrm{Sr}) \mathrm{TiO}_{3}$ and $\mathrm{Pb}(\mathrm{Zr}, \mathrm{Ti}) \mathrm{O}_{3}$, the alignment determined using transitivity with ITO or $\mathrm{RuO}_{2}$ and the alignment extracted from direct interface formation all agree within $0.2 \mathrm{eV}$, giving substantial credit to this approach. ${ }^{32}$ However, there is substantial deviation between the electrochemical alignment and those obtained by aligning the Fermi energies at interfaces with $\mathrm{RuO}_{2}$ and ITO for the materials included in Figure 10. This difference is valid even if the different magnitude of Fermi level splitting for the different oxides is taken into account. An instructive example is given by anatase and rutile $\mathrm{TiO}_{2}$, where it was shown recently using complementary approaches that the valence band of rutile is about $0.7 \mathrm{eV}$ higher than that of anatase, which substantially differs from the alignment obtained using electrochemical studies. $62,65,66$ 
With respect to $\mathrm{BiVO}_{4}$, the valence band maximum is $0.4 \mathrm{eV}$ above that of $\mathrm{SrTiO}_{3}$ according to the electrochemical alignment from flatband potential measurements. ${ }^{67,68}$ Using the $\mathrm{RuO}_{2}$ and ITO interfaces, the valence band of $\mathrm{BiVO}_{4}$ would be $0.75 / 1.25 \mathrm{eV}$ higher than that of $\mathrm{SrTiO}_{3}$. The latter alignment would correspond well with the alignment of $\mathrm{SrTiO}_{3}$ with other perovskites having $\mathrm{Bi}^{3+}$ or $\mathrm{Pb}^{2+}$ as $\mathrm{A}$-site cations. ${ }^{32,69,70}$ The higher valence band maximum of the latter perovskites is explained by the contribution of the occupied 6 s orbitals of $\mathrm{Bi}$ or $\mathrm{Pb} .{ }^{71}$ As higher valence band maxima are quite generally observed for such compounds, it seems reasonable to expect that the valence band maximum of $\mathrm{BiVO}_{4}$ is also about $1 \mathrm{eV}$ higher than that of $\mathrm{SrTiO}_{3}$, which would better agree with the alignment obtained from transitivity of $\mathrm{RuO}_{2}$ and ITO interfaces.

Using the Butler-Ginley approach, which is based on electronegativities of the involved atoms, the energy bands of $\mathrm{BiVO}_{4}$ are positioned about $0.4 \mathrm{eV}$ lower in energy compared to the electrochemical alignment shown in Figure $10 .^{72,73}$ In the light of the discussion above this seems to be unrealistic, which concurs with the observation that band positions calculated from absolute electronegativities deviate from experimental measurements for ternary oxides. ${ }^{74}$

The deviation of the energy band alignment obtained using transitivity from electrochemical or solid-state interfaces may be explained either by the presence of Fermi level pinning or by a fundamental difference between solid/electrolyte and solid/solid interfaces. For solid/solid interfaces, the presence or the degree of Fermi level pinning can be obtained by comparing the variation of the Fermi energy using contact materials with different work functions. Such experiments should, however, take into account that Fermi level pinning might also be caused by lattice defects, which are frequently introduced on oxide surfaces by metal deposition. ${ }^{31,75}$ However, even in the case of unreactive interfaces, such as those between two oxides used in the 
present study, bulk or surface defects may also result in a substantial variation of band alignment. ${ }^{56,76-78}$ As a consequence, one may expect a substantial dependence of band alignment on preparation conditions. For instance, different concentrations of oxygen vacancies in $\mathrm{ZnO}$ and metallic precipitates in $\mathrm{Cu}_{2} \mathrm{O}$ result in a variation of band alignment by more than $1 \mathrm{eV}$ at the interface between these materials. ${ }^{56}$ In contrast, the effect of defects on the band alignment at oxide/liquid interfaces has been less extensively studied.

In addition, specific surface interaction mechanisms must be considered for solid/electrolyte interfaces, which will be different in solid/solid interfaces. First of all, the substrate surface may be terminated in a different way due to specific adsorption of $\mathrm{H}^{+}, \mathrm{OH}^{-}$, or molecular $\mathrm{H}_{2} \mathrm{O}$ species from the solution phase. Specific adsorption of supporting electrolyte species and solution contaminants may also play a role. The adsorption of ionic species results in the formation of a charged inner Helmholtz layer, which does not exist in similar form on solid surfaces. Additionally, an electrochemical double layer, the outer Helmholtz layer is formed due to electrostatic attraction of charged species or dipoles in the electrolyte to the (charged) solid surface. Due to thermal diffusion and dipolar interactions this layer can extend up to several hundreds of $\mathrm{nm}$ into the electrolyte solution (Gouy-Chapman or Stern layer). Finally, the different procedures in contact formation may lead to additional differing defect formation or passivation reactions at the interface. For solid/solid interfaces, defect passivation or surface reactions typically take place during contact formation, after which the contact properties show little or no further changes. In contrast, the properties of the solid/electrolyte interface can be easily_and often reversibly_-modified afterwards by e.g. applying a potential, changing the $\mathrm{pH}$ of the solution, or by illumination in case of a semiconducting solid. 
The $\mathrm{RuO}_{2}$ interface experiment revealed an upward band bending of $0.7 \mathrm{eV}$ after the deposition of a $3 \mathrm{~nm}$ thick $\mathrm{RuO}_{2}$ film. Thus, a Schottky junction is formed that should provide effective charge carrier separation and, together with the good electrocatalytic properties, make $\mathrm{RuO}_{2}$ a suitable oxidation co-catalyst for $\mathrm{BiVO}_{4}$. Possible limitations could still be its high cost, compared to less expensive co-catalysts such as $\mathrm{CoPi}$ and $\mathrm{FeOOH} / \mathrm{NiOOH}$, and its inefficient surface passivation. ${ }^{7,10,15}$ Regarding the ITO interface, electrons should flow efficiently from $\mathrm{BiVO}_{4}$ into ITO due to the small difference in conduction band energy. This observation agrees well with the use of ITO as ohmic contact to $\mathrm{BiVO}_{4}{ }^{7,13}$

\section{CONCLUSION}

A combination of thin film sputtering and photoelectron spectroscopy was used to study the $\mathrm{BiVO}_{4} / \mathrm{RuO}_{2}$ and the $\mathrm{BiVO}_{4} / \mathrm{ITO}$ interfaces. Because of the strongly different work functions of $\mathrm{RuO}_{2}$ and ITO, different Schottky barriers were induced in $\mathrm{BiVO}_{4}$ after depositing the respective contact layers. An upwards band bending of $0.71 \mathrm{eV}$ for $\mathrm{BiVO}_{4} / \mathrm{RuO}_{2}$ and a downwards band bending of $0.16 \mathrm{eV}$ for $\mathrm{BiVO}_{4} / \mathrm{ITO}$ were observed. The difference in Schottky barrier height of $0.85 \mathrm{eV}$ is lower than what was observed in similar interface experiments on other oxide semiconductors, which indicates a partial Fermi level pinning. The assumed transitivity of the $\mathrm{RuO}_{2}$ and ITO interface experiments allowed to align $\mathrm{BiVO}_{4}$ relative to other oxides studied for photo(electro)chemical water splitting, showing that the alignment based on solid/electrolyte and solid/solid interfaces differ from each other. These findings clearly show that the alignment based on solid/electrolyte interfaces cannot be used to interpret the junctions of heterostructured materials. Thus, interface experiments, which allow the direct analysis of the contact properties 
of newly formed junctions, helps to understand such heterojunctions and may help to design more efficient photoelectrodes.

\section{ASSOCIATED CONTENT}

\section{Supporting Information}

\section{AUTHOR INFORMATION}

\section{Corresponding Author}

* Wolfram Jaegermann

E-mail: jaegermann@surface.tu-darmstadt.de; Phone number: +4961511620770

\section{Author Contributions}

The manuscript was written through contributions of all authors. All authors have given approval to the final version of the manuscript.

\section{ACKNOWLEDGMENTS}

This work was carried out in the framework of EJD-FunMat (European Joint Doctorate for Multifunctional Materials) and has received funding from the European Union's Horizon 2020 research and innovation programme under the Marie Sklodowska-Curie grant agreement No 641640. The authors acknowledge Mario Brützam and Reinhard Uecker of the Leibniz Institut für Kristallzüchtung (IKZ) in Berlin for growing and providing the molybdenum doped bismuth vanadate crystal, and Michael Kanis of the Helmholtz-Zentrum Berlin (HZB) for help with the preparation. Fuxian Wang (HZB) is acknowledged for preparing the sputtered $\mathrm{BiVO}_{4}$ films. 


\section{REFERENCES}

(1) van de Krol, R.; Parkinson, B. A. Perspectives on the Photoelectrochemical Storage of Solar Energy. MRS Energy Sustain. 2017, 4, E13.

(2) Shaner, M. R.; Atwater, H. A.; Lewis, N. S.; McFarland, E. W. A Comparative Technoeconomic Analysis of Renewable Hydrogen Production Using Solar Energy. Energy Environ. Sci. 2016, 9, 2354-2371.

(3) Fujishima, A.; Honda, K. Electrochemical Photolysis of Water at a Semiconductor Electrode. Nature 1972, 238, 37-38.

(4) Osterloh, F. E. Inorganic Materials as Catalysts for Photochemical Splitting of Water. Chem. Mater. 2008, 20, 35-54.

(5) Shockley, W.; Queisser, H. J. Detailed Balance Limit of Efficiency of $p$ - $n$ Junction Solar Cells. J. Appl. Phys. 1961, 32, 510-519.

(6) Moniz, S. J. A.; Shevlin, S. A.; Martin, D. J.; Guo, Z.-X.; Tang, J. Visible-Light Driven Heterojunction Photocatalysts for Water Splitting - a Critical Review. Energy Environ. Sci. 2015, 8, 731-759.

(7) Pihosh, Y.; Turkevych, I.; Mawatari, K.; Uemura, J.; Kazoe, Y.; Kosar, S.; Makita, K.; Sugaya, T.; Matsui, T.; Fujita, D.; et al. Photocatalytic Generation of Hydrogen by CoreShell $\mathrm{WO}_{3} / \mathrm{BiVO}_{4}$ Nanorods with Ultimate Water Splitting Efficiency. Sci. Rep. 2015, 5, 11141.

(8) Abdi, F. F.; Firet, N.; van de Krol, R. Efficient BiVO 4 Thin Film Photoanodes Modified with Cobalt Phosphate Catalyst and W-Doping. ChemCatChem 2013, 5, 490-496. 
(9) Li, R.; Han, H.; Zhang, F.; Wang, D.; Li, C. Highly Efficient Photocatalysts Constructed by Rational Assembly of Dual-Cocatalysts Separately on Different Facets of $\mathrm{BiVO}_{4}$. Energy Environ. Sci. 2014, 7, 1369.

(10) Kim, T. W.; Choi, K.-S. Nanoporous $\mathrm{BiVO}_{4}$ Photoanodes with Dual-Layer Oxygen Evolution Catalysts for Solar Water Splitting. Science 2014, 343, 990-994

(11) He, Z.; Shi, Y.; Gao, C.; Wen, L.; Chen, J.; Song, S. BiOCl/BiVO 4 P-n Heterojunction with Enhanced Photocatalytic Activity under Visible-Light Irradiation. J. Phys. Chem. C 2014, 118, 389-398.

(12) Wang, J.; Osterloh, F. E. Limiting Factors for Photochemical Charge Separation in $\mathrm{BiVO}_{4}$ $/ \mathrm{Co}_{3} \mathrm{O}_{4}$, a Highly Active Photocatalyst for Water Oxidation in Sunlight. J. Mater. Chem. $A$ 2014, 2, 9405-9411.

(13) Abdi, F. F.; Han, L.; Smets, A. H. M.; Zeman, M.; Dam, B.; van de Krol, R. Efficient Solar Water Splitting by Enhanced Charge Separation in a Bismuth Vanadate-Silicon Tandem Photoelectrode. Nat. Commun. 2013, 4, 17594-17598.

(14) Moniz, S. J. A.; Zhu, J.; Tang, J. 1D Co-Pi Modified BiVO $4 / Z n O$ Junction Cascade for Efficient Photoelectrochemical Water Cleavage. Adv. Energy Mater. 2014, 4, 1301590.

(15) Zachäus, C.; Abdi, F. F.; Peter, L. M.; van de Krol, R. Photocurrent of $\mathrm{BiVO}_{4}$ Is Limited by Surface Recombination, Not Surface Catalysis. Chem. Sci. 2017, 8, 3712-3719

(16) Resasco, J.; Zhang, H.; Kornienko, N.; Becknell, N.; Lee, H.; Guo, J.; Briseno, A. L.; Yang, P. $\mathrm{TiO}_{2} / \mathrm{BiVO}_{4}$ Nanowire Heterostructure Photoanodes Based on Type II Band Alignment. ACS Cent. Sci. 2016, 2, 80-88. 
(17) Yuan, Q.; Chen, L.; Xiong, M.; He, J.; Luo, S.-L.; Au, C.-T.; Yin, S.-F. $\mathrm{Cu}_{2} \mathrm{O} / \mathrm{BiVO}_{4}$ Heterostructures: Synthesis and Application in Simultaneous Photocatalytic Oxidation of Organic Dyes and Reduction of $\mathrm{Cr}(\mathrm{VI})$ under Visible Light. Chem. Eng. J. 2014, 255, 394-402.

(18) Gleria, M.; Memming, R. Charge Transfer Processes at Large Band Gap Semiconductor Electrodes: Reactions at SiC-Electrodes. J. Electroanal. Chem. Interfacial Electrochem. 1975, 65, 163-175.

(19) Gelderman, K.; Lee, L.; Donne, S. W. Flat-Band Potential of a Semiconductor: Using the Mott-Schottky Equation. J. Chem. Educ. 2007, 84, 685.

(20) Gerischer, H. Electrolytic Decomposition and Photodecomposition of Compound Semiconductors in Contact with Electrolytes. J. Vac. Sci. Technol. 1978, 15, 1422-1428.

(21) Serpone, N.; Pelizzetti, E. Photocatalysis : Fundamentals and Applications; Wiley: New York, 1989.

(22) Sakata, T.; Kawai, T. 10 - Photosynthesis and Photocatalysis with Semiconductor Powders. In Energy Resources Through Photochemistry and Catalysis; Academic Press, 1983; pp 331-358.

(23) Kudo, A.; Miseki, Y.; Uetsuda, H.; Onishi, H.; Morton, O.; Torimoto, T.; Kudo, A.; Kuwabata, S.; Domen, K.; Li, C.; et al. Heterogeneous Photocatalyst Materials for Water Splitting. Chem. Soc. Rev. 2009, 38, 253-278.

(24) Sivula, K.; van de Krol, R. Semiconducting Materials for Photoelectrochemical Energy Conversion. Nat. Rev. Mater. 2016, 1, 15010. 
(25) Harris, L. A.; Wilson, R. H. Semiconductors for Photoelectrolysis. Annu. Rev. Mater. Sci. 1978, 8, 99-134.

(26) Ding, C.; Shi, J.; Wang, D.; Wang, Z.; Wang, N.; Liu, G.; Xiong, F.; Li, C. Visible Light Driven Overall Water Splitting Using cocatalyst/BiVO ${ }_{4}$ Photoanode with Minimized Bias. Phys. Chem. Chem. Phys. 2013, 15, 4589.

(27) Jaegermann, W. Surface Studies of Layered Materials in Relation to Energy Converting Interfaces. In Photoelectrochemistry and Photovoltaics of Layered Semiconductors; Kluwer Academic Publishers: Dordrecht, the Netherlands, 1992; pp 195-295.

(28) Cardon, F.; Gomes, W. P. On the Determination of the Flat-Band Potential of a Semiconductor in Contact with a Metal or an Electrolyte from the Mott-Schottky Plot. $J$. Phys. D. Appl. Phys. 1978, 11, L63-L67.

(29) Klein, A. Energy Band Alignment at Interfaces of Semiconducting Oxides: A Review of Experimental Determination Using Photoelectron Spectroscopy and Comparison with Theoretical Predictions by the Electron Affinity Rule, Charge Neutrality Levels, and the Common Anion Rule. Thin Solid Films 2012, 520, 3721-3728.

(30) Jaegermann, W. The Semiconductor/Electrolyte Interface: A Surface Science Approach. In Modern aspects of Electrochemistry; Plenum Press: New York, 1996; pp 1-185.

(31) Klein, A. Interface Properties of Dielectric Oxides. J. Am. Ceram. Soc. 2016, 99, 369387.

(32) Schafranek, R.; Li, S.; Chen, F.; Wu, W.; Klein, A. $\mathrm{PbTiO}_{3} / \mathrm{SrTiO}_{3 \mathrm{v}}$ Interface: Energy Band Alignment and Its Relation to the Limits of Fermi Level Variation. Phys. Rev. B 
2011, $84,45317$.

(33) Man, I. C.; Su, H.-Y.; Calle-Vallejo, F.; Hansen, H. A.; Martínez, J. I.; Inoglu, N. G.; Kitchin, J.; Jaramillo, T. F.; Nørskov, J. K.; Rossmeisl, J. Universality in Oxygen Evolution Electrocatalysis on Oxide Surfaces. ChemCatChem 2011, 3, 1159-1165.

(34) Wang, Q.; Hisatomi, T.; Jia, Q.; Tokudome, H.; Zhong, M.; Wang, C.; Pan, Z.; Takata, T.; Nakabayashi, M.; Shibata, N.; et al. Scalable Water Splitting on Particulate Photocatalyst Sheets with a Solar-to-Hydrogen Energy Conversion Efficiency Exceeding 1\%. Nat. Mater. 2016, 15, 611-615.

(35) Lin, F.; Wang, D.; Jiang, Z.; Ma, Y.; Li, J.; Li, R.; Li, C.; Luan, G. Y.; Takata, T.; Hara, M.; et al. Photocatalytic Oxidation of Thiophene on $\mathrm{BiVO}_{4}$ with Dual Co-Catalysts Pt and $\mathrm{RuO}_{2}$ under Visible Light Irradiation Using Molecular Oxygen as Oxidant. Energy Environ. Sci. 2012, 5, 6400-6406.

(36) Chen, Z.; Li, W.; Li, R.; Zhang, Y.; Xu, G.; Cheng, H. Fabrication of Highly Transparent and Conductive Indium-Tin Oxide Thin Films with a High Figure of Merit via Solution Processing. Langmuir 2013, 29, 13836-13842.

(37) Lany, S.; Zunger, A. Dopability, Intrinsic Conductivity, and Nonstoichiometry of Transparent Conducting Oxides. Phys. Rev. Lett. 2007, 98, 45501.

(38) Klein, A.; Körber, C.; Wachau, A.; Säuberlich, F.; Gassenbauer, Y.; Harvey, S. P.; Proffit, D. E.; Mason, T. O. Transparent Conducting Oxides for Photovoltaics: Manipulation of Fermi Level, Work Function and Energy Band Alignment. Materials (Basel). 2010, 3, $4892-4914$. 
(39) Wu, X.; Zhou, J.; Duda, A.; Keane, J. C.; Gessert, T. A.; Yan, Y.; Noufi, R. 13·9\%Efficient CdTe Polycrystalline Thin-Film Solar Cells with an Infrared Transmission of 50\%. Prog. Photovoltaics Res. Appl. 2006, 14, 471-483.

(40) Lee, Y.-L.; Chi, C.-F.; Liau, S.-Y. CdS/CdSe Co-Sensitized $\mathrm{TiO}_{2}$ Photoelectrode for Efficient Hydrogen Generation in a Photoelectrochemical Cell ${ }^{\dagger}$. Chem. Mater. 2010, 22, 922-927.

(41) Gong, H.; Freudenberg, N.; Nie, M.; van de Krol, R.; Ellmer, K. BiVO 4 Photoanodes for Water Splitting with High Injection Efficiency, Deposited by Reactive Magnetron CoSputtering. AIP Adv. 2016, 6, 45108 .

(42) Wendler, E., M. Bischoff, E. Schmidt, F. Schrempel, K. Ellmer, M. K. and van de Krol, R. Ion Beam Modification of Single Crystalline BiVO 4 . Nucl. Instr. Meth. B 2017, 409, 133137

(43) Klein, A. Transparent Conducting Oxides: Electronic Structure-Property Relationship from Photoelectron Spectroscopy with in Situ Sample Preparation. J. Am. Ceram. Soc. 2013, 96, 331-345.

(44) Moulder, J. F.; Chastain, J.; King, R. C. Handbook of X-Ray Photoelectron Spectroscopy: A Reference Book of Standard Spectra for Identification and Interpretation of XPS Data; Physical Electronics: Eden Prairie MN, 1995.

(45) Chen, L.; Alarco-Llado, E.; Hettick, M.; Sharp, I. D.; Lin, Y.; Javey, A.; Ager, J. W.; Alarcón-Lladó, E.; Hettick, M.; Sharp, I. D.; et al. Reactive Sputtering of Bismuth Vanadate Photoanodes for Solar Water Splitting. J. Phys. Chem. C 2013, 117, 21635- 
21642.

(46) Liang, Y.; Tsubota, T.; Mooij, L. P. A.; van de Krol, R. Highly Improved Quantum Efficiencies for Thin Film BiVO 4 Photoanodes. J. Phys. Chem. C 2011, 115, 17594 17598.

(47) Yu, J.; Kudo, A. Effects of Structural Variation on the Photocatalytic Performance of Hydrothermally Synthesized BiVO 4 . Adv. Funct. Mater. 2006, 16, 2163-2169.

(48) Su, J.; Zou, X.-X.; Li, G.-D.; Wei, X.; Yan, C.; Wang, Y.-N.; Zhao, J.; Zhou, L.-J.; Chen, J.-S. Macroporous $\mathrm{V}_{2} \mathrm{O}_{5} / \mathrm{BiVO}_{4}$ Composites: Effect of Heterojunction on the Behavior of Photogenerated Charges. J. Phys. Chem. C 2011, 115, 8064-8071.

(49) Fritsche, J.; Schulmeyer, T.; Thißen, A.; Klein, A.; Jaegermann, W. Interface Modification of CdTe Thin Film Solar Cells by $\mathrm{CdCl}_{2}$-Activation. Thin Solid Films 2003, 431, 267-271.

(50) Waldrop, J. R.; Kraut, E. A.; Kowalczyk, S. P.; Grant, R. W. Valence-Band Discontinuities for Abrupt (110), (100), and (111) Oriented Ge-GaAs Heterojunctions. Surf. Sci. 1983, 132, 513-518.

(51) Walsh, A.; Da Silva, J. L. F.; Wei, S.-H.; Körber, C.; Klein, A.; Piper, L. F. J.; DeMasi, A.; Smith, K. E.; Panaccione, G.; Torelli, P.; et al. Nature of the Band Gap of $\operatorname{In}_{2} \mathrm{O}_{3}$ Revealed by First-Principles Calculations and X-Ray Spectroscopy. Phys. Rev. Lett. 2008, $100,167402$.

(52) Saimi Tokunaga; Hideki Kato, and; Kudo*, A.; Kudo, A. Selective Preparation of Monoclinic and Tetragonal $\mathrm{BiVO}_{4}$ with Scheelite Structure and Their Photocatalytic 
Properties. Chem. Mater. 2001, 13, 4624-2628.

(53) Pelizzetti, E.; Visca, M. 8 - Bifunctional Redox Catalysis: Synthesis and Operation in Water-Cleavage Reactions. In Energy Resources Through Photochemistry and Catalysis; Academic Press, 1983; pp 261-296.

(54) Mönch, W. Electronic Properties of Semiconductor Interfaces; Springer: Berlin, 2004.

(55) Klein, A.; Lohaus, C.; Reiser, P.; Dimesso, L.; Wang, X.; Yang, T. Energy Band Alignment of Antiferroelectric (Pb,La)(Zr,Sn,Ti)O 3 . Appl. Surf. Sci. 2017, 407, 99-104.

(56) Siol, S.; Hellmann, J. C.; Tilley, S. D.; Graetzel, M.; Morasch, J.; Deuermeier, J.; Jaegermann, W.; Klein, A. Band Alignment Engineering at $\mathrm{Cu}_{2} \mathrm{O} / \mathrm{ZnO}$ Heterointerfaces. ACS Appl. Mater. Interfaces 2016, 8, 21824-21831.

(57) Klein, A. Energy Band Alignment in Chalcogenide Thin Film Solar Cells from Photoelectron Spectroscopy. J. Phys. Condens. Matter 2015, 27, 134201.

(58) Tersoff, J. Schottky Barrier Heights and the Continuum of Gap States. Phys. Rev. Lett. 1984, 52, 465-468.

(59) Spicer, W. E.; Kendelewicz, T.; Newman, N.; Cao, R.; McCants, C.; Miyano, K.; Lindau, I.; Liliental-Weber, Z.; Weber, E. R. The Advanced Unified Defect Model and Its Applications. Appl. Surf. Sci. 1988, 33-34, 1009-1029.

(60) Chen, F.; Schafranek, R.; Wu, W.; Klein, A. Reduction-Induced Fermi Level Pinning at the Interfaces between $\mathrm{Pb}(\mathrm{Zr}, \mathrm{Ti}) \mathrm{O}_{3}$ and $\mathrm{Pt}, \mathrm{Cu}$ and $\mathrm{Ag}$ Metal Electrodes. J. Phys. D. Appl. Phys. 2011, 44, 255301. 
(61) Körber, C.; Harvey, S. P.; Mason, T. O.; Klein, A. Barrier Heights at the $\mathrm{SnO}_{2} / \mathrm{Pt}$ Interface: In Situ Photoemission and Electrical Properties. Surf. Sci. 2008, 602, 32463252.

(62) Pfeifer, V.; Erhart, P.; Li, S.; Rachut, K.; Morasch, J.; Brötz, J.; Reckers, P.; Mayer, T.; Rühle, S.; Zaban, A.; et al. Energy Band Alignment between Anatase and Rutile $\mathrm{TiO}_{2}$. J. Phys. Chem. Lett. 2013, 4, 4182-4187.

(63) Giesecke, R.; Hertwig, R.; Bayer, T. J. M.; Randall, C. A.; Klein, A. Modification of the Schottky Barrier Height at the $\mathrm{RuO}_{2}$ Cathode during Resistance Degradation of Fe-Doped $\mathrm{SrTiO}_{3} . J$. Am. Ceram. Soc. 2017, 100, 4590-4601.

(64) Li, S.; Ghinea, C.; Bayer, T. J. M.; Motzko, M.; Schafranek, R.; Klein, A. Electrical Properties of $(\mathrm{Ba}, \mathrm{Sr}) \mathrm{TiO}_{3}$ Thin Films with Pt and ITO Electrodes: Dielectric and Rectifying Behaviour. J. Phys. Condens. Matter 2011, 23, 334202.

(65) Deák, P.; Aradi, B.; Frauenheim, T. Band Lineup and Charge Carrier Separation in Mixed Rutile-Anatase Systems. J. Phys. Chem. C 2011, 115, 3443-3446.

(66) Scanlon, D. O.; Dunnill, C. W.; Buckeridge, J.; Shevlin, S. A.; Logsdail, A. J.; Woodley, S. M.; Catlow, C. R. A.; Powell, M. J.; Palgrave, R. G.; Parkin, I. P.; et al. Band Alignment of Rutile and Anatase $\mathrm{TiO}_{2}$. Nat. Mater. 2013, 12, 798-801.

(67) Hong, S. J.; Lee, S.; Jang, J. S.; Lee, J. S.; Yan, M.; Gaillard, N.; Garland, R.; Takanabe, K.; Heske, C.; Sunkara, M.; et al. Heterojunction $\mathrm{BiVO}_{4} / \mathrm{WO}_{3}$ Electrodes for Enhanced Photoactivity of Water Oxidation. Energy Environ. Sci. 2011, 4, 1781.

(68) Nozik, A. J. Photoelectrochemistry: Applications to Solar Energy Conversion. Annu. Rev. 
Phys. Chem. 1978, 29, 189-222.

(69) Li, S.; Chen, F.; Schafranek, R.; Bayer, T. J. M.; Rachut, K.; Fuchs, A.; Siol, S.; Weidner, M.; Hohmann, M.; Pfeifer, V.; et al. Intrinsic Energy Band Alignment of Functional Oxides. Phys. status solidi - Rapid Res. Lett. 2014, 8, 571-576.

(70) Li, S.; Morasch, J.; Klein, A.; Chirila, C.; Pintilie, L.; Jia, L.; Ellmer, K.; Naderer, M.; Reichmann, K.; Gröting, M.; et al. Influence of Orbital Contributions to the Valence Band Alignment of $\mathrm{Bi}_{2} \mathrm{O}_{3}, \mathrm{Fe}_{2} \mathrm{O}_{3}, \mathrm{BiFeO}_{3}$, and $\mathrm{Bi}_{0.5} \mathrm{Na}_{0.5} \mathrm{TiO}_{3}$. Phys. Rev. B 2013, 88, 45428.

(71) Walsh, A.; Payne, D. J.; Egdell, R. G.; Watson, G. W. Stereochemistry of Post-Transition Metal Oxides: Revision of the Classical Lone Pair Model. Chem. Soc. Rev. 2011, 40, 4455.

(72) Ding, K.; Chen, B.; Li, Y.; Zhang, Y.; Chen, Z. Comparative Density Functional Theory Study on the Electronic and Optical Properties of $\mathrm{BiMO}_{4}(\mathrm{M}=\mathrm{V}, \mathrm{Nb}, \mathrm{Ta})$. J. Mater. Chem. A 2014, 2, 8294.

(73) Long, M.; Cai, W.; Cai, J.; Zhou, B.; Chai, X.; Wu, Y. Efficient Photocatalytic Degradation of Phenol over $\mathrm{Co}_{3} \mathrm{O}_{4} / \mathrm{BiVO}_{4}$ Composite under Visible Light Irradiation. J. Phys. Chem. B 2006, 110, 20211-20216.

(74) Xu, Y.; Schoonen, M. A. A. The Absolute Energy Positions of Conduction and Valence Bands of Selected Semiconducting Minerals. Am. Mineral. 2000, 85, 543 .

(75) Brillson, L. J. Transition in Schottky Barrier Formation with Chemical Reactivity; Springer, Dordrecht, 1990; pp 138-141.

(76) Brillson, L. J.; Dong, Y.; Tuomisto, F.; Svensson, B. G.; Kuznetsov, A. Y.; Doutt, D.; 
Mosbacker, H. L.; Cantwell, G.; Zhang, J.; Song, J. J.; et al. Interplay of Native Point Defects with ZnO Schottky Barriers and Doping. J. Vac. Sci. Technol. B, Nanotechnol. Microelectron. Mater. Process. Meas. Phenom. 2012, 30, 50801.

(77) Brillson, L. J.; Lu, Y. ZnO Schottky Barriers and Ohmic Contacts. J. Appl. Phys. 2011, 109, 121301.

(78) Allen, M. W.; Durbin, S. M. Influence of Oxygen Vacancies on Schottky Contacts to ZnO. Appl. Phys. Lett. 2008, 92, 122110.

\section{SYNOPSIS}

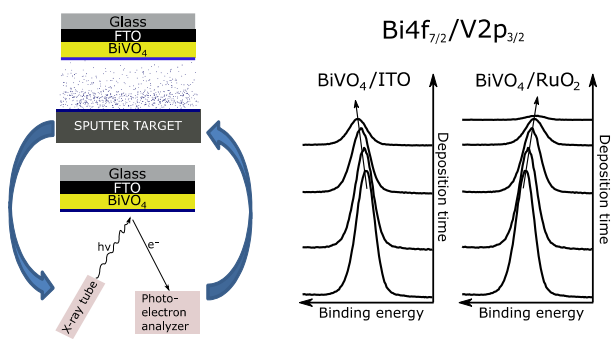

